Exploring the Relationship Betw een

Exclusive TalentM anagem ent, Perceived

O rganizational đustice and Em ployee

Engagem ent:Bridging the Literature

Edw ard P . O 'C onnor \& M arian C row leyH enry

JoumalofBusiness Ethics

ISSN 0167-4544

JBusEthics

DO I10 1007/s10551-017-3543-1

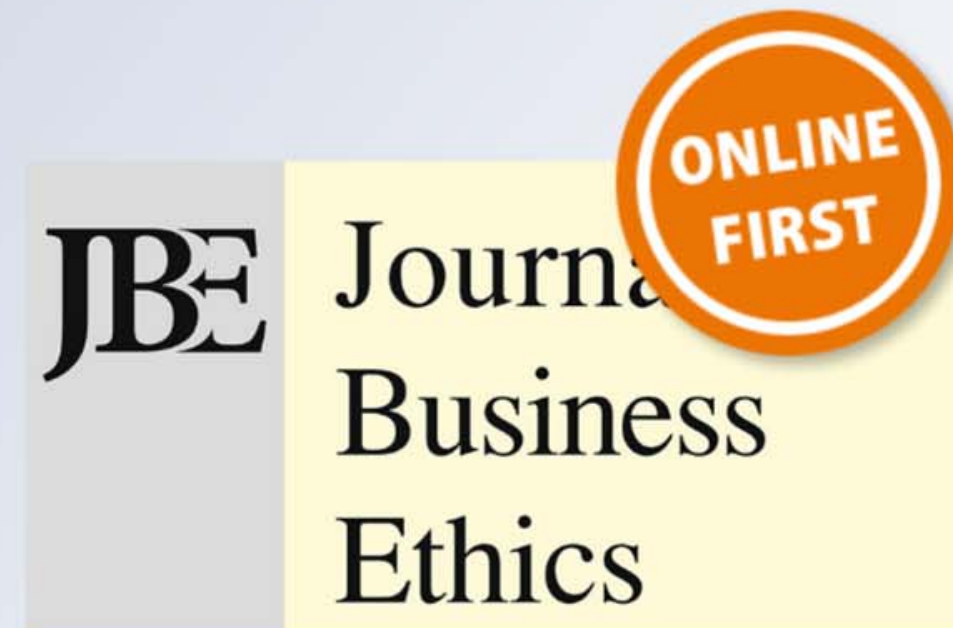

Yolume 142, Na
April (11) 2017

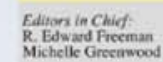

ISSN 0167-4544

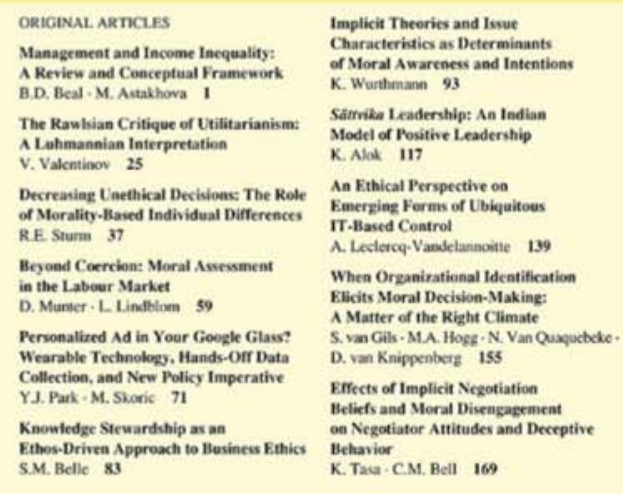

$\underline{\text { Springer }}$ 


\title{
Exploring the Relationship Between Exclusive Talent Management, Perceived Organizational Justice and Employee Engagement: Bridging the Literature
}

\author{
Edward P. O’Connor ${ }^{1} \cdot$ Marian Crowley-Henry ${ }^{1}$
}

\begin{abstract}
This conceptual paper explores the relationship between an organization's exclusive talent management (TM) practices, employees' perceptions of the fairness of exclusive TM practices, and the corresponding impact on employee engagement. We propose that in organizations pursuing exclusive TM programs, employee perceptions of organizational justice of the exclusive TM practices may affect their employee engagement, which may influence both organizational and employee outcomes. Building on extant research, we present a conceptual framework depicting the relationship between exclusive TM practices, organizational justice and employee engagement, with social exchange theory and equity theory as the framework's foundation. The propositions in the framework are each supported by the respective literature. The perceived organizational justice and potential ramifications of exclusive TM practices for employees who are not included in corporate talent pools is an under-researched topic. The paper considers the perspectives of employees not included in corporate talent pools and explores how exclusive TM practices, as inputs, could lead to negative employee engagement outputs. In unpacking how exclusive TM practices could impact on employee engagement, the implications for organizations are underlined. The ethics and perceived fairness of exclusive TM practices, which have the potential to marginalize employees and lead to their disengagement, are considered.
\end{abstract}

\footnotetext{
\& Edward P. O’Connor

EDWARD.OCONNOR.2011@mumail.ie

Marian Crowley-Henry

Marian.CrowleyHenry@nuim.ie

1 School of Business, Maynooth University, Maynooth, Co. Kildare, Ireland
}

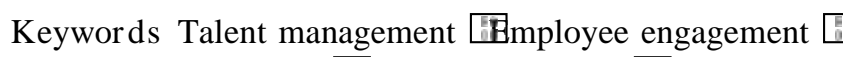
Organizational justice 5 istributive justice 5 Procedural justice Thteractional justice IS $_{\text {ocial exchange theory }}$ Equity theory $\mathrm{FH}_{\mathrm{H}}$ uman resource management $\mathrm{F}$ thics

\section{Introduction}

Exclusive talent management (TM) - the human resource management (HRM) strategies, policies and practices where organizations identify and focus resources on a limited number of 'talented' employees, that is high-performing (Lewis and Heckman 2006), or high-potential employees (Gallardo-Gallardo et al. 2013)—has received limited consideration from an ethical and organizational justice (Greenberg 1990) standpoint in the business and management literature. Greenwood (2002) underlines the relevance of ethics and justice in HRM. More recently, Gelens et al. (2013, 2014) unpack the role of perceived organizational justice in shaping TM outcomes. Similarly, Lacey and Groves (2014) and Swailes (2013a) have initiated discussion on the ethics and fairness of TM practices. Nonetheless, there remains a gap in more fully examining the exclusive TM phenomenon from an ethical and organizational justice standpoint. There is a particular dearth of studies concerning the effects of exclusive TM practices at the micro (individual employee) level (Meyers et al. 2015), with a pressing need for TM research to place greater emphasis on employee welfare issues, such as perceived fairness (Tansley et al. 2013).

This paper's focus is on exploring these gaps in the literature, in considering the relationship between exclusive TM, perceived organizational justice and employee engagement. In bridging the literature between TM and employee engagement, we add to the extant research, in 
line with Gelens et al. (2013, 2014), who explore how perceived organizational justice shapes TM outcomes, and He et al. (2014), who unpack the effects of perceived organizational justice on employee engagement. Our paper, arguing that the perceived fairness, equity and justice of TM practices is an important area of ethical concern, explores the possible negative outcomes for the individual employee resulting from perceived unethical TM practices, with a focus on the specific TM outcome of employee engagement. Our paper addresses the micro-level discussion on the effects and consequences of exclusive TM by theorizing, through the lenses of equity theory (Adams 1963) and SET theory (Blau 1964), how exclusive TM practices may affect the employee engagement of 'nontalented' employees.

Consistent with Hayibor's (2017, p. 49) assertion that 'a deficiency in the fairness-based perspective' is its assumption of homogeneity, we reject that all employees perceive the fairness of TM in the same way. We accept that not all employees may be interested in being in talent pools and that not all organizations utilize workforce differentiation. Therefore, we focus directly on the perceptions of employees who are in organizations where exclusive TM practices are followed; who are not included in the organization's identified talent pool; and who would like to be included, and indeed assume they deserve to be included, in the organization's talent pool. By concentrating on this sub-group, we differentiate this paper from previous studies which treated those excluded from the talent program (the majority of employees) in a homogenous manner. We explore the role of ethics in an organizational context, where employees may perceive their exclusion from talent management pools as unfair and unjust. The theoretical contribution of the analysis and propositions is relevant, in unpacking organizational justice to propose how perceptions of the fairness of exclusive TM (as inputs) can impact upon employee engagement (as an output). The resultant theoretical conceptualization, extending on Gelens et al. (2014) and built up from relevant literature on organizational justice, exclusive TM, and employee engagement, is shared in the paper.

Exclusive TM, commonly practiced in organizations today (Malik and Singh 2014; Swailes et al. 2014), is at the crux of our conceptualization. Existing TM studies have tended to focus on the positive side of the practice, such as the potential for substantial positive impact on the organization's performance (Bhatnagar 2007; Thunnissen et al. 2013), while ignoring the potential detrimental impact on those not identified as 'talented' (Marescaux et al. 2013; Meyers et al. 2015). Lacey and Groves (2014) bemoan the hypocrisy of organizations pursuing corporate social responsibility (CSR) policies targeted at all stakeholders, while simultaneously practicing exclusive TM and denying the majority of employees, who are an important stakeholder group (Collier and Esteban 2007), access to targeted development opportunities. In this way, an elitist (Swailes 2013a), two-tier system and inherent workforce differentiation (Lepak and Snell 1999) is perpetuated.

Employers have a moral responsibility to care for their employees and 'opportunities for employee development form part of the overall package of care' (Swailes 2013a, p. 37). However, as a minority group, 'talented' employees have a disproportionate amount of development resources invested in their future (Malik and Singh 2014; Swailes 2013a). This proactive workforce differentiation raises ethical questions, where the dehumanizing effect of exclusive TM is propounded at the individual level, with those regarded as 'non-talented' excluded, denied individual agency and labeled inferior (Swailes 2013a). Exclusive TM has negative consequences for employee inclusion and diversity, marginalizing and sometimes neglecting the majority of employees (Sheehan and Anderson 2015), with those excluded 'harmed by actions done in the name of boosting organizational performance' (Swailes 2013a, p. 37). This majority cohort includes some of those with most to benefit from investment in their development and future, such as those with untapped or unrecognized 'talent'. It also includes all other employees who should have the right to development opportunities and better terms and conditions, in accordance with the principles of inclusive TM (Festing et al. 2013; Lewis and Heckman 2006; Swailes et al. 2014). Additionally, the appraisal of employee performance and potential, the main form of talent identification, can be highly political and prone to bias, leading to what employees may perceive as unfair practices (Buckley et al. 2001; Soni 2014).

Minbaeva and Collings (2013) argue that one of the myths regarding $\mathrm{TM}$ is the seemingly unquestioned assumption that talent decisions are fair. Cosier and Dalton (1983) stress the importance of fairness and equity in the workplace, forewarning of potentially dramatic ramifications from an organization's mismanagement of these concepts. Likewise, Van Buren III (2008) has highlighted that organizational justice should be at least a secondary consideration in management practices in order to be considered socially legitimate. Fairness, an essential principle in ethical leadership (Buckley et al. 2001; He et al. 2014; Soni 2014), normally provokes positive employee responses (Thornton and Rupp 2016). However, employee responses to perceived fairness often correspond to their organizational experiences (Cropanzano and Mitchell 2005), with 'low perceptions of fairness likely to cause employees to withdraw and disengage’ (Saks 2006, p. 606). This aligns with Roof's (2015) contention that a core 
ethical calling of leaders is to endeavor to 'satisfy employees' higher order needs through elevated employee engagement' (Roof 2015, p. 586). Thus, we argue that the practice of exclusive TM requires unpacking from a fairness standpoint, taking into account the perceived fairness, equity and justice of TM practices as perceived by employees who are excluded from TM programs.

The objectives of this paper are twofold: firstly, to explore exclusive TM practices and the perceived organizational justice of these practices through social exchange theory and equity theory lenses; and secondly, to propose potential effects on individual employee engagement resulting from perceived unethical TM practices. The paper develops our contention by putting forward a conceptual framework and propositions for empirical testing, which link exclusive TM practices, the input, as having an effect on corresponding employee engagement levels, the output. This relationship is mediated by employee perceptions of distributive justice, which, in turn, are moderated by perceptions of procedural (Marescaux et al. 2013) and interactional justice (Gelens et al. 2013; 2014). Distributive, procedural and interactional justice is applied in the paper to illustrate the nuances to employee perceptions and reactions to exclusive TM practices (see also, Gelens et al. 2013, 2014). In the theoretical conceptualization, the act of, and responses to, exclusive TM in the sphere of exchange theories and justice are constructed from social exchange theory (SET) (Blau 1964; Emerson 1976; Gouldner 1960; Homans 1958) and equity theory (Adams 1963). Specifically, SET (Blau 1964) and equity theory (Adams 1963) are utilized to explore the volition that individual employees have toward their engagement with organizational practices, and to consider the implications of exclusive TM practices on the 'implicit social contract between an organization and its employees' (Slack et al. 2015, p. 537). This is in keeping with recent research by He et al. (2014) and Slack et al. (2015), who employ SET to unpack the effects that perceived organizational justice and employee reactions to organizational HRM practices have on employee engagement with their respective organizations’ practices.

The remainder of the paper is structured as follows. We begin with a presentation of the relevant literature, which informs the propositions' development later in the paper. Firstly, we describe exclusive TM and the existing nuances in the developing literature on TM. Next we unpack the core assumptions of SET and equity theory, and then we outline the importance of employee perceptions of HR practices (exclusive TM being a collection of HR practices targeted at an exclusive group of employees). Literature on organizational justice and employee engagement is shared, and then we present the conceptual framework. Thereafter the implications of our contribution to theory and practice are discussed before, finally, setting out the limitations of the paper and the scope for further research.

\section{Talent Management}

Over the last decade, TM has received a large amount of interest, from both practitioners and academics alike (Collings and Mellahi 2009; Sheehan and Anderson 2015), and is now recognized as a key management issue (Thunnissen et al. 2013). Yet, despite this interest, the concept still lacks an accepted definition and distinct conceptual boundaries (Collings and Mellahi 2009; Festing and Schäfer 2014). The definition of TM adopted in this paper is the commonly used Collings and Mellahi (2009) definition, which aligns with the exclusive TM practice of using a select pool of 'talented' appointees to fill 'key positions'. They define TM as

activities and processes that involve the systematic identification of key positions that differentially contribute to the organization's sustainable competitive advantage, the development of a talent pool of high-potential and high-performing incumbents to fill these roles, and the development of a differentiated human resource architecture to facilitate filling these positions with competent incumbents, and to ensure their continued commitment to the organization (Collings and Mellahi 2009, p. 304).

Scholars have recently begun to unpack TM and its ambiguities (see Collings et al. 2015 for a detailed review of TM). For the purposes of this paper, the focus is on the inclusive/exclusive dichotomy in TM research, the most debated tension in the literature (Gallardo-Gallardo et al. 2013).

The exclusive perspective singles out a limited number of 'talented' employees to belong to a talent pool, while the inclusive perspective includes all employees in the organization's overall TM strategy, with developmental pathways for all employees (Collings and Mellahi 2009; Dries 2013; Swailes et al. 2014). Inclusive TM follows the general rule that all employees have their own strengths and are talented in their own way (Collings et al. 2015). It is an ethical HRM principle that all employees' performances are to be valued and managed, and they should have the opportunity to be part of the organization's talent program (Swailes et al. 2014). Conversely the exclusive view, which regards some workers as more talented, and valuable than others (Dries 2013), is seen by some as being the main difference between TM and HRM (Collings and Mellahi 2009). The exclusive approach to TM has become the more practiced form in organizations today (Garavan et al. 2012), mainly due to perceived cost-effectiveness and 
efficiency (Huselid and Becker 2011; Marescaux et al. 2013). While Swailes (2013b) notes that examples of inclusive TM in practice are scarce, examples, such as the preference for inclusive TM in German small to medium enterprises (Festing et al. 2013) and the inclusive TM processes of the British National Health Service (Swailes 2013a), do exist. Sheehan and Anderson (2015) note that the direction of recent HRM literature, similar to exclusive TM, is toward a more differentiated and exclusive style of HRM. It is within this context of increasing focus on exclusivity and differentiation that our conceptualization is situated.

Exclusive TM, as part of the inclusive/exclusive tension in TM research, sits among five inter-related tensions in TM research (Dries 2013). The other four tensions are firstly the subjective-objective view of talent. The subjective view focuses on identifying and developing 'talented' people, while the objective focus concentrates on the characteristics of talent, which are reified in high-performance and high-potential employees (Iles et al. 2010). This perspective focuses on high-performing or high-potential employees, with the selection and identification of these exclusive employees raising ethical questions concerning hidden biases and workforce homogeneity. Second, the innate versus acquired perspective centers on the extent to which talent can be taught or learned (Dries 2013; Meyers et al. 2013). The innate perspective concentrates on the identification and selection of 'talented' employees, an exclusive perspective that resonates with our focus on exclusive TM, and with hidden bias in terms of talent recognition in organizations. The acquired perspective, while assuming that talent may be developed, does not unpack the mechanisms through which employees are selected for development, which may again be subject to hidden biases in the organization.

The third tension is the input versus output perspective, where the central issue is whether talent depends more on ability or motivation (Gallardo-Gallardo et al. 2013). This tension conflicts with the premise of SET, as the input versus output perspective considers ability and motivation separately, rather than considering the complexity of the relational and reflexive relationship between ability and motivation in a social organizational setting. Fourth, the transferable versus context-dependent perspective looks at the physical boundaries of talent. The transferable view posits that 'talented' employees will demonstrate their talents and abilities regardless of the context or environment in which they are operating (Cappelli 2008). The context-dependent view assumes there is an important link between 'talented' employees and the context and that talent is not always readily transferable. Consequently, a lack of fit between the employee and organizational environment may inhibit talent. This perspective sets TM firmly within a particular organizational, professional and/or country context, which is relevant for our study in terms of equity theory and how fairness may be perceived by employees in different settings. These nuances to TM theorization underline the academic development of TM into a more comprehensive and reflexive body of work, which has yet to reach maturity.

This paper, focusing on exclusive TM practices, argues that despite the popularity of exclusive TM practices, the effects of categorizing a small percentage of the workforce as 'talented' and restricting the majority of employees from privileged development opportunities (Lacey and Groves 2014) are problematic and raise ethical questions (Swailes 2013a). SET (Blau 1964) and equity theory (Adams 1963), described next, are utilized to unpack the implications of exclusive TM practices on the individual employee's engagement with their organization and its practices.

\section{Social Exchange Theory (SET) and Equity Theory}

SET (Blau 1964; Emerson 1976; Gouldner 1960; Homans 1958;1961) and equity theory (Adams 1963) have been used to explore organizational justice and employee reactions to organizational HRM practices (for example Gelens et al. 2013; He et al. 2014; Masterson et al. 2000). This paper utilizes SET and equity theory to explore the effects of perceived organizational justice on employee reactions (specifically, employee engagement) to organizational HRM practices (specifically, exclusive TM practices); thereby linking the three constructs of exclusive TM, perceived organizational justice, and employee engagement and attempting to unpack the theoretical relationship between them.

Much of the early work on organizational justice draws on SET (Blau 1964; Colquitt et al. 2001), which is built on the principles of reciprocity and social indebtedness (Gouldner 1960; Haynie et al. 2016). While there have been differing views on what social exchange entails, most theorists concur that social exchange involves interactions that generate obligations (Cropanzano and Mitchell 2005; Emerson 1976). Blau (1964) is among the first of the theorists to distinguish between exchanges where the nature of the obligations are specific and purely economic, and those that were less specific and more social or emotional. SET helps us to unpack and understand how employee perceptions of organizational TM practices may generate either positive or negative attitudes and responses to the TM practices (Björkman et al. 2013; Khoreva et al. 2017). Saks (2006) contends that SET provides a 'meaningful theoretical basis for understanding and studying employee engagement' (Saks 2006, p. 616), as SET helps explain why, when employees perceive that their relationship with 
their employer is fair and just, they will reciprocate in kind, such as with positive behaviors (Blau 1964; Gouldner 1960).

It is these aspects of SET that help explain why an employee's organizational commitment is dependent upon their perception of the value and fairness of the organization's actions as part of their relationship (Collier and Esteban 2007), or as Slack et al. (2015, p. 537) proclaim the 'implicit social contract between an organization and its employees'. The level of employee motivation for discretionary organizational efforts will vary, with this variance dependent on the strength of the employee's social commitment to the organization. Meanwhile, the strength of the employee's social commitment to the organization will depend on how fair, or balanced, the employee perceives that their organizational efforts and commitments are being reciprocated by the organization (Saks 2006). Blau (1964) emphasizes the role and importance of this perception of balance in social exchange relationships, with a perceived lack of balance in an employment relationship causing negative impacts on employee effort and commitment. For instance, as suggested in this paper, how employees who are interested in being part of their organization's talent pool, but are not identified as 'talented', may perceive that the organization has not fulfilled their side of the exchange relationship, and thus their relationship becomes unbalanced (Blau 1964), which could provoke them to respond with counterproductive attitudes in an attempt to rebalance the relationship (Godkin 2014; Hurrell 2016).

Adams' (1963) equity theory, 'a dominant theory in social exchange and justice in organizations' (Glass and Wood 1996, p. 1191), is subjective and perception based. Equity theory contends that employees are not concerned with final levels of outcome, but motivated by a pursuit of fairness and are thus more concerned with how fair (they perceive) their outcomes to be (Hofmans 2012). Employees will seek to uphold what they perceive to be a fair balance between what they put into an organization, their inputs, and what they receive in return or as reward, their outputs (Pritchard 1968). This input/output ratio is compared to the input/output ratio of 'referent' others, who are fellow employees considered similar to themselves (Adams 1963).

Equity theory helps explain the psychological processes shaping the employees' reactions to being classified as 'non-talented', as they strive to uphold what they perceive to a fair balance between their organizational inputs and outputs. We contend that employees classified as 'nontalented', but who believe they should be identified as 'talented', will compare their input/output ratio to that of those who were identified as 'talented' and included in the organization's talent pool. From this comparison, employees will form a perception of whether the talent program was fair and just. If the employee perceives the program as unfair or unjust, that it is lacking in justice (Greenberg 1990; He et al. 2014), this will impact on the individual's relationship with the organization. In turn, this could lead to negative outcomes, such as a lowering of work effort, particularly discretionary work effort, or organizational commitment (Cohen-Charash and Spector 2001; Ghosh et al. 2014; Marescaux et al. 2013). Lack of fairness in organizational practices may also lead to harmful and unethical retaliatory behaviors (Skarlicki and Folger 1997), another potential implication of exclusive TM practices. Therefore, employee perception, described next, plays an important role in our use of SET and equity theory as the theoretical foundations for our conceptualization, showing the relationship between exclusive TM, organizational justice and employee engagement.

\section{Employee Perceptions}

Employee perceptions of their organization's HR practices influence employee reactions to the HR practices (Gelens et al. 2013; Kinnie et al. 2005; Swailes 2013b; Wright and Nishii 2006). These perceptions are the outcome of a threestep process: the intended practice, the actual practice and the perceived practice (Wright and Nishii 2006; Wright and Snell 1998). See Fig. 1 below.

Unpacking how employees may react to the perceived effects of the organization's practices is fundamental for our conceptualization. Applying this process to the conceptualization and resultant framework, the intended HRM practice represents the organization's planned exclusive TM program, which is designed to identify 'talented' employees and include them in the organizational talent pool. However, due to a number of influences, such as institutional or political factors, not all HR practices are

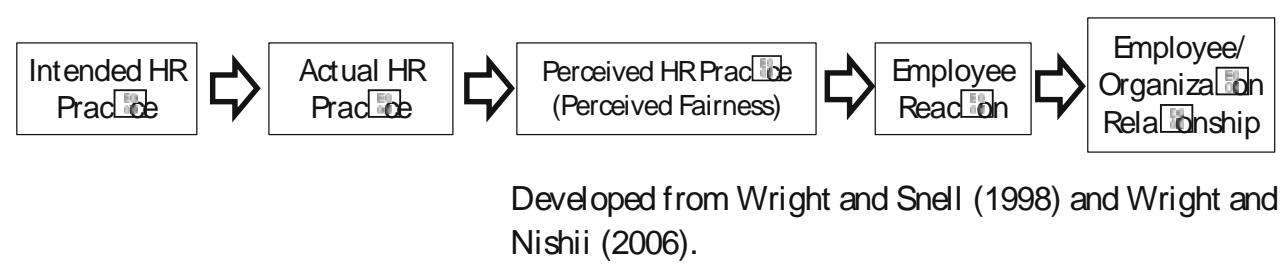

Fig. 1 Process model of employee perceptions. Developed from Wright and Snell (1998), Wright and Nishii (2006) 
actually implemented in the intended manner, resulting in a difference between the espoused practice and the actual practice (Mintzberg 1978; Wright and Snell 1998). While actual HR practices exist objectively, they are interpreted and perceived by each individual employee, creating a subjective experience. This perception affects the employee's reactions, which in turn may affect the employment relationship and its outcomes, such as employee engagement, in either a positive or negative manner (Björkman et al. 2013; Ghosh et al. 2014; Khoreva et al. 2017; Wright and Nishii 2006). Employee perceptions of organizational justice, which is described next, mediate and moderate the relationship between the organization's TM practices and the employee's reactions to these TM practices (Gelens et al. 2013, 2014).

\section{Organizational Justice}

The ideals of organizational justice have long been recognized as a foundation for the effective functioning of organizations and the personal satisfaction of their employees (Greenberg 1990). Developed from early theories of social justice, such as Adams (1963) equity theory and Homan's (1961) distributive justice theory, organizational justice (Greenberg 1990) can be defined as the degree to which an employee believes their relationship with their organization is fair, equitable and ethical (Cropanzano et al. 2007; Greenberg 1990; Malik and Singh 2014). A tripartite concept, organizational justice is made up of distributive justice, procedural justice and interactional justice. Distributive justice, which originates from Adams' (1963) equity theory and Leventhal's (1976) justice judgement model (Greenberg 1990), is founded on the premise that human social behavior is 'conditioned by the distribution of outcomes' (Ghosh et al. 2014, p. 631). Distributive justice considers the degree to which the distribution, or allocation, of outcomes (such as promotions, rewards) is fair (Adams 1963; Colquitt 2001; Hofmans 2012). Procedural justice, the perceived justice and fairness of the allocation process, extends the study of distributive justice (Greenberg and Folger 1983; Leventhal 1980). Research has shown that the distribution of outcomes (such as pay, promotion) is not always as important as the fairness of the allocation process of the outcomes (CohenCharash and Spector 2001; Wan et al. 2012). Finally, interactional justice (Bies 1987; Bies and Moag 1986) is based on the perceived quality of the interpersonal treatment people receive while practices are being implemented. Interactional justice operates on the premise that employees' perceptions of fairness take into account the manner of communication and information sharing which is used and is in essence made up of two separate forms of justice (Greenberg 1990; Colquitt 2001): interpersonal justice, relating to the dignity and respect employees receive from those in authority and informational justice, relating to how well employees are informed about matters that affect them.

Two important considerations when examining the effects of organizational justice are the order and cumulative effects of the concept (Gelens et al. 2013). While the various forms of justice are accepted as distinct concepts in their own right, there is evidence of a dependent relationship (Skarlicki and Folger 1997) between the concepts, particularly between procedural and distributive justice. The order in which practices, information and planned outcomes are revealed to employees will also impact on the employees' perceptions of justice (Cropanzano et al. 2007; Folger 1986).

In keeping with the extant literature, we maintain that perceptions of organizational justice are the link between exclusive TM and its effects on employee engagement (Biswas et al. 2013; Cropanzano et al. 2007; Gelens et al. 2014; He et al. 2014; Schminke et al. 2014). Perceptions of organizational justice are the employee's subjective perception of their employee-organizational relationship (Greenberg 1990) and are directly related to the quality of this relationship (Masterson et al. 2000; Purang 2011). Justice plays a particularly important role in employee career development (Wooten and Cobb 1999), especially in areas concerning the perceived fairness of organizational decisions affecting employees or their colleagues (Malik and Singh 2014). If employees perceive their employer's TM program as unfair, this may have a negative effect on their perceptions of organizational justice (Gelens et al. 2014; Malik and Singh 2014). As stated above, the quality of the social exchanges between the individual and their organization can be directly affected by these perceptions of organizational justice. Therefore, employee/organizational outcomes, such as employee engagement, may also be negatively affected by perceptions of organizational justice (Biswas et al. 2013; Frank et al. 2004; Ghosh et al. 2014; He et al. 2014; Malik and Singh 2014).

An important consideration for our conceptualization of the effects of exclusive TM on employee engagement is how an employee's perceptions of organizational justice can moderate their actions and responses. Distributive justice was found to have a greater effect at the microlevel, such as on employee job engagement (Greenberg 1990; Ghosh et al. 2014; McFarlin and Sweeney 1992), while perceptions of procedural justice have been found to have a greater effect at the meso-level, such as on organizational engagement (Cropanzano and Folger 1991; McFarlin and Sweeney 1992; Saks 2006). For instance, employees, who are provided with appropriate information, transparent procedures and fair treatment before any HRM decisions are made, and they understand the whole process, 
may have a positive reaction to HRM programs, even if the outcome is not favorable to them. However, an issue inhibiting the effective use of this possible buffer to perceived injustice is the secrecy under which some organizations operate their HRM (including specific TM) systems (Gelens et al. 2013, 2014; Lacey and Groves 2014), which can prohibit the provision of clear information and open procedures.

Findings by Jepsen and Rodwell (2012) suggest that gender may also have an effect on perceptions of justice, with the different sexes affected differently by different forms of justice. This is not surprising as gender inequalities were found to be a major impairment for development and meritocracy in the female workforce (Anker 2004; Tatli et al. 2013), and there is a call for gender differences to be considered in future organizational justice research (Jepsen and Rodwell 2012). Given that our analysis is conceptual in nature, our research echoes this call, as our paper will be strengthened by empirical research among employees with different characteristics in order to further unpack variance and potential inequality.

\section{Employee Engagement}

Employee engagement, regarded as crucial for an organization's success (Rich et al. 2010), has seen a surge of interest in human resource development (HRD) circles and has been the subject of extensive research in recent years (Ghosh et al. 2014; Roof 2015; Saks and Gruman 2014). With the importance of discretionary effort in the attainment of organizational goals (Thomas and Rowland 2014), employee engagement has become an important organizational measurement, with implications for competitive performance. The extant literature advances a link between employee engagement and organizational justice (Li 2012), with perceived organizational justice found to be an important element in employee engagement (He et al. 2014). Equity theory and SET provide theoretical explanations for employee engagement in discretionary activities (as contended by Agarwal 2014, Biswas et al. 2013, Ghosh et al. 2014, He et al. 2014, Li 2012, Saks 2006).

Multiple definitions of employee engagement exist (Saks 2006), with a general lack of consensus in the literature on what employee engagement actually means (Shuck 2011; Shuck and Reio 2014). Saks and Gruman (2014) highlight two influential definitions of engagement in the academic literature, from Kahn (1990) and Maslach et al. (2001). Maslach et al. (2001) define employee engagement as 'an energetic state of involvement with personally fulfilling activities that enhance one's sense of professional efficacy' (Maslach et al. 2001, p. 498), with engagement characterized by 'energy, involvement, and efficacy'. This defines engagement as the positive antithesis of job burnout and burnout's three dimensions of exhaustion, cynicism, and inefficacy (Maslach et al. 2001). This paper utilizes Kahn’s (1990) widely used definition (Ghosh et al. 2014; Godkin 2014; He et al. 2014; Roof 2015), which is 'the simultaneous employment and expression of a person's 'preferred self' in task behaviors that promote connections to work and to others, personal presence (physical, cognitive and emotional), and active, full performances' (Kahn 1990, p. 700). Kahn's definition is preferred for our study as his description of engagement involving an 'employee's full self in terms of physical, cognitive, and emotional energies to work role performances' (Rich et al. 2010, p. 617) portrays engagement as a 'true psychological presence at and identity with work' (Macey and Schneider 2008, p. 12), one which goes beyond basic employee motivation, with engaged employees fully investing their 'hands, head, and heart' into an active, full work performance (Ashforth and Humphrey 1995, p. 110). Empirical research has linked investments of these three energies (physical, cognitive, and emotional) to job performance and employee engagement (Kahn 1990; May et al. 2004; Rich et al. 2010; Thomas and Rowland 2014). Kahn (1990) also contends that three psychological states-meaningfulness, safety and availability-are needed for engagement to happen, with all three psychological states important constructs in creating an engaged workforce (Harter et al. 2002; Shuck 2011). Meaningfulness is when employees feel worthwhile, appreciated and not taken for granted, with all their efforts, both physical and emotional, recognized and rewarded. Safety is when employees can commit themselves fully and freely to their role, without fearing negative consequences and feel their organization is supportive and trusting. Finally, availability concerns how ready employees are to become engaged and committed to their role, and depends on employees having all the necessary resources and supports (physical, emotional or psychological) needed to cope with both work and non-work aspects of their lives.

Engaged employees are fully committed to and motivated by contributing to and achieving organizational goals, but importantly they also achieve self-satisfaction and feeling of worth in a reciprocal relationship with the organization (Ashforth and Humphrey 1995; Kahn 1990; Maslach et al. 2001; Saks and Gruman 2014; Schaufeli et al. 2002; Shuck 2011). The importance of employees' self-satisfaction and feeling of worth in a reciprocal relationship with the organization is reflected in employee engagement and perceived organizational justice, as explained through SET and equity theory. 


\section{Toward the Conceptualization}

SET and equity theory (Adams 1963; Blau 1964; Hofmans 2012; Slack et al. 2015) are founded on the premise that employees seek to uphold what they perceive to be a fair balance between their organizational inputs, and what they receive in return or as reward, with equity theory allowing for comparison with referent others. Each employee will perceive whether their inputs are, or are not, reciprocated by the organization, and therefore will experience either more favorable or less favorable perceptions of fairness and justice (Adams 1963; Colquitt 2001). Following on from this, we propose that in organizations utilizing exclusive TM practices, these practices may result in different perceptions of distributive justice for different groups of employees, in this case, employees not identified as 'talented', but who are concerned with being part of the talent pool program. Figure 2 (below) sets out our conceptual framework, constructed from unpacking propositions on exclusive TM, perceived organizational justice and employee engagement.

It is important to appreciate that there are many different sub-groupings of employees in organizations, with these sub-groupings based on either objective or subjective (beliefs and attitudes) criteria. Sub-groups based on objective criteria include those considered 'talented' and considered objectively deserving of being included in the organization's talent pool; those considered 'talented', but when compared to referent others considered to not warrant being in the organization's talent pool, and those not considered 'talented' and objectively excluded from the organization's talent pool for objective reasons. However, as the appraisal of employee potential and performance is frequently based on biased decision-making (Swailes 2013a), the objectivity of some organizations' TM decisions is open to question.

The TM practices of an organization will be individually interpreted and perceived by each employee and, from this subjective experience, each employee will shape their own reaction to the actual practice. Therefore, as the focus of this paper is to understand the relationship between an organization's exclusive TM practices, employees' perceptions of the fairness of the exclusive TM practices, and the corresponding impact on employee engagement, our focus is on the sub-group based on the subjective criteria of employee beliefs and attitudes, specifically employees not labeled as 'talented', but who believe they should be part of the talent pool when compared to referent others.

Extant research contends that the unequal distribution of resources that exclusive TM entails will have a positive

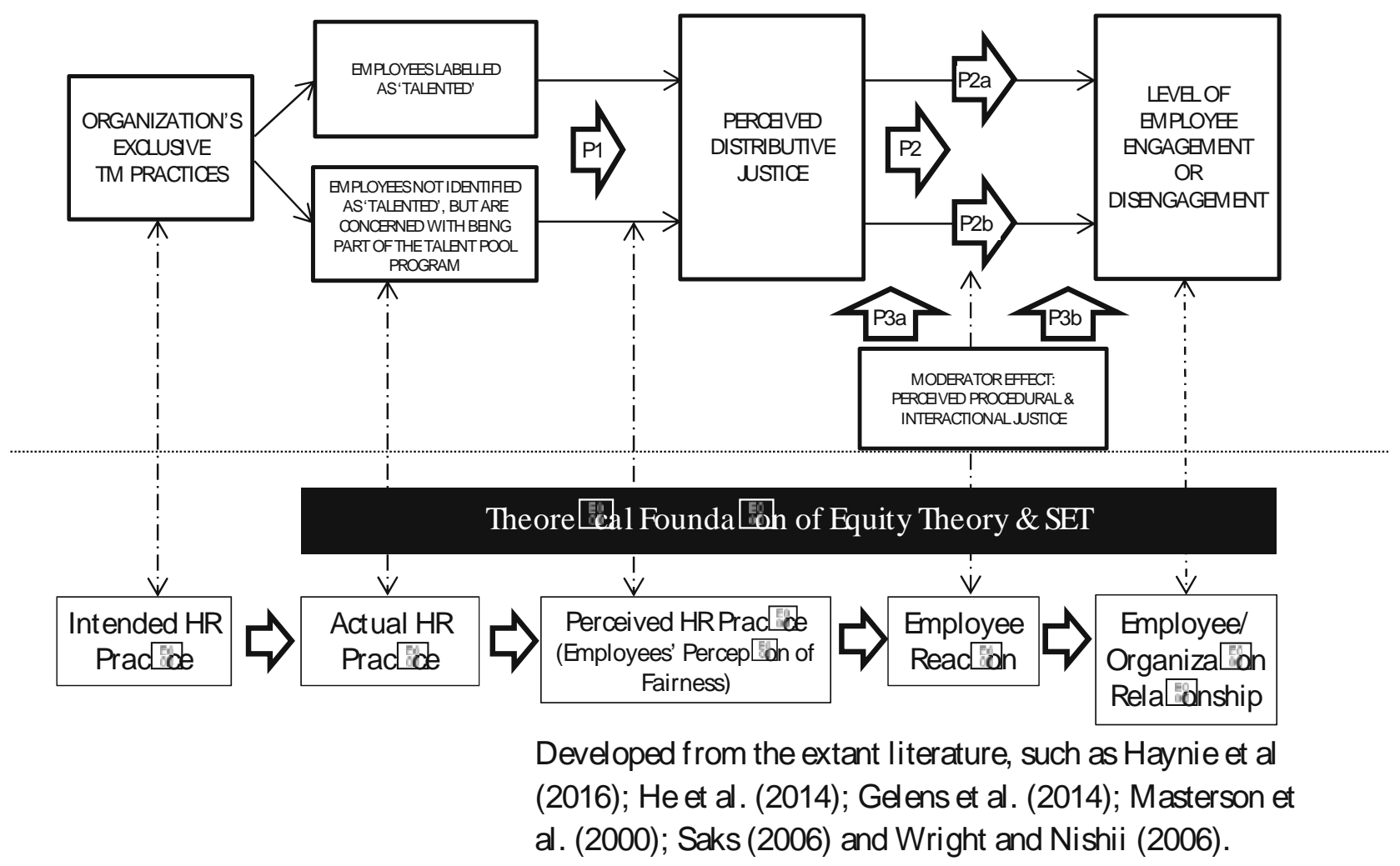

Fig. 2 Conceptual framework with parallel model of employee perceptions. Developed from the extant literature, such as Haynie et al. (2016), He et al. (2014), Gelens et al. (2014), Masterson et al. (2000), Saks (2006) and Wright and Nishii (2006) 
effect on the employees categorized as 'talented', creating a positive perception of the value and fairness of the organization's actions as part of their relationship (Björkman et al. 2013; Collier and Esteban 2007; Gelens et al. 2014; Marescaux et al. 2013; Slack et al. 2015). Therefore, employees who are identified as 'talented' will perceive that the organization has fulfilled their side of the exchange relationship, and will experience more favorable perceptions of distributive justice (Erdogan 2002; Gelens et al. 2014; Ghosh et al. 2014).

Conversely, our contention is that the unequal distribution of resources, that exclusive TM entails, will have a negative effect on the employees who are not identified as 'talented', but are concerned with being part of the talent pool program. For this sub-group, this will create a negative perception of the value and fairness of the organization's actions as part of their relationship (Björkman et al. 2013; Gelens et al. 2014; Marescaux et al. 2013) and from this they will perceive that their inputs have not been justly rewarded and that the organization is not reciprocating their efforts in a fair or just manner. They will perceive this as a lack of distributive justice (Erdogan 2002; He et al. 2014), which will impact on the individual's relationship with the organization. This is the basis of our first proposition.

P1. Employees identified as 'talented' will be more likely to perceive higher levels of distributive justice than employees who are not identified as 'talented', but who are concerned with being part of the talent pool program. On the other hand, employees who are not identified as 'talented', but who are concerned with being part of the talent pool program, are more likely to perceive lower levels of distributive justice.

Perceptions of justice shape employee reactions (Cropanzano and Folger 1991) and perceived organizational justice is found to be an important element in employee engagement (He et al. 2014). Therefore, we contend that employees' perceptions of their respective organization's exclusive TM practices, via the mediating role of distributive justice, will have an instrumental effect on their level of engagement. Using SET as a theoretical explanation, and building on previous works of academics such as Agarwal (2014), Biswas et al. (2013), Cropanzano et al. (2007), Gelens et al. (2013), He et al. (2014), Li (2012), Marescaux et al. (2013), O’Connor and CrowleyHenry (2015) and Purang (2011), we contend that employees identified as 'talented', because of their higher perceptions of distributive justice, will show higher levels of engagement. However, employees not identified as 'talented', but who are concerned with being part of the corporate talent pool program, will show lower levels of engagement due to their lower perceptions of distributive justice. For the latter cohort, the employee perceives an input/output imbalance in their relationship with their employer, where they may perceive that the efforts they have invested in the employing organization are not justly rewarded or recognized by their employer (He et al. 2014). The employee will seek to rebalance the relationship, as they will want the exchange relationship to be what they perceive as fair. This rebalancing may provoke a response of counterproductive attitudes and behaviors (Godkin 2014; Hurrell 2016; Saks 2006). This can result in increased employee turnover (Swailes and Blackburn 2016) and a lowering of work effort (Saks 2006), commitment and engagement (Cohen-Charash and Spector 2001; Ghosh et al. 2014; Marescaux et al. 2013). This is the basis of our second proposition, and its respective subpropositions

P2. Perceived distributive justice mediates the relationship between exclusive TM practices and employee engagement.

P2a. In particular, employees identified as 'talented', because of their higher perceptions of distributive justice, will show higher levels of engagement.

P2b. While employees who are not identified as 'talented', but who are concerned with being part of the talent pool program, and who perceive their identification as 'non-talented' to be unfair, will show lower levels of engagement.

In further unpacking the different dimensions of organizational justice, we consider how these may also influence the employees' reactions to the organizational practices of exclusive TM, potentially moderating the relationship between perceived distributive justice and employee engagement. Therefore, due to this moderating effect, we postulate that employees, who are treated with respect (interpersonal injustice), provided with appropriate information (informational justice), and transparent and fair procedures (procedural justice), before any TM decisions are made regarding who is included and excluded in the organizational talent pool, and who understand the whole process, will have a more positive reaction to announced TM outcomes (that is, the identities of those selected for the organization's HiPo talent pool), even if the outcome is not favorable to them (Biswas et al. 2013; Gelens et al. 2014; Ghosh et al. 2014). Findings from other studies suggest that it is an organization's HRM procedures, and not the actual HRM content, that have a greater influence on employee reactions, which suggests that perceptions of procedural justice influence employee reactions to HRM programs (Cohen-Charash and Spector 2001; Katou 2013; Wan et al. 2012). 
In line with Gelens et al. (2013, 2014) and Marescaux et al. (2013), we posit that both procedural and interactional justice, respectively, moderate the extent to which perceived distributive (in)justice impacts upon work outcomes, with our focus here on employee engagement. When employees perceive high levels of procedural and interactional justice, the resultant effects on employee engagement will be neutral to positive. On the other hand, when employees perceive low levels of procedural and interactional justice, the effects on employee engagement will be negative. However, as previously outlined, a potential obstacle to the procedural and interactional justice buffer (Gelens et al. 2013) between perceived distributive (in)justice and employee engagement is the secrecy under which some organizations operate their TM systems (Gelens et al. 2013, 2014; Lacey and Groves 2014), which may prohibit the provision of clear information and transparent procedures.

Therefore, we contend that employees, those who are concerned with being part of the talent pool program but are not recognized by the organization as 'talented', will feel unfairly treated if they perceive that the information or notice they receive regarding the organization's talent management program is incomplete, not timely or lacking in detail (informational injustice) and/or if the information is presented to them in an affected manner or one that is lacking in respect toward their efforts and concern with being part of the talent pool (interpersonal injustice). Negative perceptions of unfair interactional or procedural justice may provoke a stronger negative employee reaction to perceptions of unfair distributive justice in a desire to rebalance the relationship and perceived inequity. Conversely, an employee's engagement will be less negatively affected if they perceive that the organization's procedural and allocation process are fair and transparent (Biswas et al. 2013; Gelens et al. 2014; Ghosh et al. 2014; Katou 2013). This is the basis of our third proposition and its subpropositions.

P3. The perceived justice and fairness of both the allocation process (procedural justice) and the interpersonal treatment people receive (interactional justice) while TM programs are being implemented, will have a moderating effect on the relationship between distributive justice and employee engagement.

P3a. When employees perceive high levels of procedural and/or interactional justice, the resultant effects on employee engagement will be neutral to positive.

P3b. Conversely, when employees perceive low levels of procedural and interactional justice, the effects on employee engagement will be negative.
The conceptual model, constructed from the previously shared three propositions, which originated from findings in the extant literature, is presented in Fig. 2. The model provides a framework that explores the relationship between an organization's exclusive talent management (TM) practices, employees' perceptions of the organizational justice of exclusive TM practices, and the corresponding impact on employee engagement. Next, we discuss this conceptualization further.

\section{Discussion and Conclusion}

The aim of this paper is to explore, from a micro-level/ individual employee perspective, the relationship between exclusive talent management, perceived organizational justice and employee engagement. The impact of exclusive TM practices on employees' perceptions of justice and fairness is essential at the meso-level for organizations to understand, as these impacts can have significant practical consequences in terms of employee and organizational outcomes, including discretionary effort (Thomas and Rowland 2014) and employee engagement (He et al. 2014).

The organizational practice of exclusive TM, where only some select employees are considered 'talented' or 'more talented', rendering the 'non-talented' employees to question the fairness and justness of such practices (Gelens et al. 2013; Sheehan and Anderson 2015), requires deeper attention from an ethics standpoint. It raises ethical concerns at the individual, inter-group and organizational levels when this two-tier categorization of employees potentially harms those who are excluded from talent management programs by its inherent elitism and discrimination (Swailes 2013a). In our analysis in this paper, we propose that those 'harmed' employees respond by trying to rebalance the social exchange they have with their organization, which may result in reduced employee engagement. Since ethical concerns are used as a foundation from which to develop minimum standards to evaluate HRM practices (Greenwood 2002), this suggests that the conceptualization is also important in developing and encouraging further research and discussion on both the ethics and business outcomes of exclusive TM practices. We contend that these ethical issues concerning exclusive TM can lead to an absence of perceived justice in an organization's HRM practices, and that this can lead to negative micro- and meso-level outcomes, such as in reduced employee engagement and increased employee turnover rates. This suggests an organizational and leadership disconnect between the intended ethical practices of inclusion, and the actual practices of exclusion as reified in exclusive TM.

Firstly, we suggest that employees identified as 'talented' will have more favorable perceptions of distributive 
justice, while employees not identified as 'talented', but who are concerned with being part of the talent pool program will have less favorable perceptions of distributive justice. Secondly, we propound that perceived distributive justice mediates the relationship between exclusive TM practices and employee engagement, where those identified as 'talented' will show higher levels of engagement, and those identified as 'non-talented' will show lower levels of engagement. Thirdly, we argue that both procedural and interactional justice will have a moderating effect between the employee's perception of distributive justice and employee engagement.

Our propositions are in line with Gelens et al. (2013, 2014) and supported by the findings of Ghosh et al. (2014), He et al. (2014) and Saks (2006) that the various forms of justice predict and determine employee engagement. The propositions are also consistent with the work of Wooten and Cobb (1999) who assert that organizational practices and career development interventions are 'prone to perceptions of distributive, procedural and interactional fairness' (Wooten and Cobb 1999, p. 177) by employees. Existing studies also link the organizational commitment of employees to their perception of the value and fairness of their organization's actions (Björkman et al. 2013; Gelens et al. 2014; Slack et al. 2015). However, our research reveals a gap in the literature, on both the organizational justice and ethics of exclusive TM, and the impact of exclusive TM on employees not considered 'talented'. This paper contributes to addressing this gap by engaging in micro (employee)-level analysis of how exclusive TM practices, as inputs, may lead to positive or negative employee engagement outputs, and makes an important contribution to the recently begun, but limited, debate on the organizational justice and ethics of exclusive TM (see, for example, Downs and Swailes 2013; Lacey and Groves 2014; Swailes 2013a). While not all employees are troubled over exclusive TM (Swailes 2013a), this paper concentrates on those who are concerned with their selection (or not) for TM programs, and considers how these employees' perceptions of organizational justice toward them (in being 'talented' or not) impacts on their workplace engagement.

The overarching premise in this paper is that employees, who are recognized by the organization as 'talented', will have a positive perception of the value and fairness of the organization's actions as part of their relationship (Björkman et al. 2013; Gelens et al. 2014; Marescaux et al. 2013; Slack et al. 2015). In being included in the talent pool, they will experience greater perceived organizational support, recognition and development, leading to greater organizational commitment (Gelens et al. 2014; Marescaux et al. 2013; Vosloban 2013), lower turnover intentions (Björkman et al. 2013; Snell 2009) and higher perceptions of justice (Gelens et al. 2014) and fairness (Ghosh et al. 2014). As these have been recognized as antecedents to engagement (Saks 2006; Vosloban 2013), we contend that exclusive TM affects employee engagement (Huselid and Becker 2011; O’Connor and Crowley-Henry 2015).

Conversely, employees, who are identified as 'non-talented' but consider themselves as 'talented', are likely to negatively react to the perceived injustice of this nonrecognition (Gelens et al. 2014; Lacey and Groves 2014; Malik and Singh 2014; Marescaux et al. 2013). Employee reactions to perceived injustice have been found to result in dissatisfaction (Wan et al. 2012), low commitment and poor performance (Mahajan and Benson 2013), with some employees withdrawing and becoming disengaged (Frank et al. 2004; Ghosh et al. 2014; Saks 2006). This supports Marescaux et al.'s (2013) finding that workforce differentiation, which is at the core of exclusive TM, leads to negative employee and organizational outcomes.

As shown earlier in the paper, there is often a difference between espoused, actual and perceived HRM practices, with existing research suggesting that even the best planned TM strategies could result in consequences the organization did not envisage. As noted by Marescaux et al. (2013), the existing research in TM and workforce differentiation tends to focus on the positive side, such as costeffectiveness and retention (Collings and Mellahi 2009; Huselid and Becker 2011). However, some authors argue that the unseen costs of exclusive TM, such as high rates of turnover among the 'non-talented', are not taken into account in the assessment of exclusive TM (Pfeffer 2001), with workforce differentiation becoming a 'double-edged sword' as the losses among employees identified as 'nontalented' may minimize or even outweigh the benefits accrued from the increased performance of those identified as 'talented' (Marescaux et al. 2013). This argument has led to a call for TM to be understood as a relational construct (Al Ariss et al. 2014), where, individual, organizational, institutional and national relationships are taken into account. This would involve researching further how employees perceive their respective talents are being managed in the organization and their varying reactions to these perceptions. This is an important effect of workforce differentiation that has been under-explored to date (Huselid and Becker 2011).

\section{Contribution and Implications for Practice}

In unpacking how exclusive TM practices can impact on employee engagement, through the mediating and moderating role of perceived organizational justice, the paper has practical relevance for organizations, specifically for Human Resource (HR) practitioners and organizational 
leaders in highlighting the relationships between specific HR practices and employee/organizational outcomes (employee engagement and its organizational effects) at both the micro- and meso-levels. The conceptualization is also relevant for academics in the HRM domain in presenting the nuances in the relationship between exclusive TM, organizational justice and employee engagement. The paper contributes directly to the literature on TM, particularly on exclusive TM, by highlighting ethical concerns with exclusive TM practices (perceived organizational justice) and business ramifications (implications on employee engagement).

Decision makers for HRM programs and practices within organizations and those responsible for the implementation of TM procedures should consider a balanced representation of the potential ramifications of exclusive TM practices from the perspectives of all employees affected by these TM practices. An important consideration for organizations, when regarding the effects of exclusive TM on all employees, is how an employee's perceptions of organizational justice can moderate their actions and responses to the TM practice. The literature suggests that open and fair procedures should be available to, and understood by, all employees who are interested in a talent management program. In reality many organizations cannot provide all their employees with all the supports and outcomes they may perceive that they deserve (such as, in this paper, inclusion in the organization's exclusive talent pool), but what they can offer all employees are transparent, fair and open opportunities for development and promotion. Our contention is that if employees perceive that the procedures for choosing who is part of the talent program (procedural justice) are fair, and they are treated with dignity, respect and are informed about procedures and processes that affect them (interactional justice), that they will be more satisfied with the outcomes reached (distributive justice), even if the outcomes are less than favorable for them. Therefore, procedural and interactional justice may be used as a moderating buffer against the negative effects of perceptions of distributive injustice. This is developed through our propositions and presented in our conceptual framework (see Fig. 2).

When implementing TM practices, HR managers and practitioners should emphasize consistency and transparency in their practices. They should elucidate and be open about their TM procedures, creating awareness among employees. Only then can fairness become a positive influence on employee perceptions. The order effect of justice is vital at this stage. Employees must be provided with the clear and transparent procedures, and be treated equitably and with respect before the actual selection or commencement of the talent management program (that is, whether or not they are included in the talent pool).
Finally, when organizations implement TM programs, it is important that they use selection procedures that permit those the organization considers 'non-talented' to demonstrate their potential contributions. This will display fair procedures for all employees, and will affect the input/ output ratio perceptions of employees, as they will perceive that their organizational relationship is based on fair and open procedures, and thus will be less likely to form negative perceptions of justice.

\section{Limitations and Recommendations for Future Research}

This is a conceptual paper, with the conceptual framework developed from the extant literature across exclusive TM, organizational justice and employee engagement. The propositions which form the basis of the framework serve as researchable propositions for future research. Empirical testing is required to validate the propositions made in this paper. This testing could take the research approach of an employee survey, collecting data on the TM practices in a particular organization, whether or not the respective employee is included in the talent pool (along the lines of the survey conducted by Gelens et al. 2014), whether the employee is concerned with being part of the talent pool, employee perceptions concerning the TM program and procedures, and their resultant engagement levels. Such a study on a large scale could determine the different subgroups within organizations (such as those considered 'talented', or those who considered 'non-talented' but who are concerned with being part of the corporate talent pool program) as well as other particular characteristics (such as age, gender or nationality) in order to unpack intersectionality nuances. The survey could be designed to identify how the organization's talent management program impacts employees' perceived organizational justice and, in turn, their levels of employee engagement. These constructs are measurable with proven scales, such as the Rich et al. (2010) scale for employee engagement and the Colquitt (2001) scale for organizational justice.

Such a study could be augmented by qualitative interviews with a purposefully chosen sample. This would give a deeper understanding of the individual employee's perceptions of the organizational practices and their reactions to these practices, allowing for a richer interpretation of the implications and effects of exclusive TM and perceived organizational justice on employee engagement. As these perceptions and reactions are subjective, an in-depth qualitative study would allow a deeper understanding of how, at employee level, TM practices influence employee perceptions, and how these perceptions influence the employee's reactions. 
Given that gender may have an effect on employees' perceptions of justice (Jepsen and Rodwell 2012), a limitation of this study is that our framework makes no allowance for possible gender (or other individual attributes and characteristics) differences. This will need to be examined further and will have to be controlled for in future testing, as gender inequalities have been found to be a significant impairment for recruitment, development and meritocracy within the female workforce (Anker 2004; Tatli et al. 2013).

A further limitation of our paper is at the unit of analysis and discussion. Addressing a gap in the reviewed literature, the framework focuses on micro-level analysis and does not develop or discuss in depth the meso-perspective from the organization's viewpoint with regards to the organization's TM practices. While one could argue that exclusive TM, through the creation of competition among employees, has positive motivational effects and performance implications, with a trend among employees to request 'more individual treatment and recognition based on their distinct competencies and needs' (Gelens et al.2013, p. 342), this would need to be empirically tested and weighted against the potential negative implications discussed in this paper. Another limitation is that the extant research fails to focus on the wider macro-level societal ramifications of exclusive TM practices on workforce discrimination and inequality.

There is much scope here for other researchers to extend the discussions in this paper to a multi-level domain, exploring the spill-over effects of exclusive TM practices across the individual employee, organizational and societal levels. Our propositions do, however, suggest the organizational implications of employee engagement, rendering the model of importance for organizations, as levels of individual employee engagement will result in meso-level effects for the organization.

Overall, the paper encourages further research and more discussion in the area, particularly on the effects on the individual workers categorized as 'non-talented'. Our review lays the foundation for future empirical work to test the propositions that have been presented, with further work and review required to deepen the understanding of potential outcomes from the organizational practices of exclusive TM, for the betterment of individual employees, organizations, and ultimately society.

\section{References}

Adams, J. S. (1963). Towards an understanding of inequity. Journal of Abnormal and Social Psychology, 67, 422-436.

Agarwal, U. A. (2014). Linking justice, trust and innovative work behaviour to work engagement. Personnel Review, 43(1), 41-73.
Al Ariss, A., Cascio, W., \& Paauwe, J. (2014). Talent management: Current theories and future research directions. Journal of World Business, 49(2), 173-179.

Anker, R. (2004). Gender and jobs: Sex segregation of occupations in the world. Geneva: International labour office.

Ashforth, B. E., \& Humphrey, R. H. (1995). Emotion in the workplace. Human Relations, 48(2), 97-125.

Bhatnagar, J. (2007). Talent management strategy of employee engagement in Indian ITES employees: Key to retention. Employee Relations, 29(6), 640-663.

Bies, R. J. (1987). The predicament of injustice: The management of moral outrage. In L. L. Cummings \& B. M. Staw (Eds.), Research in organizational behavior (pp. 289-319). Greenwich, CT: JAI Press.

Bies, R. J., \& Moag, J. S. (1986). Interactional justice: Communication criteria of fairness. Greenwich, CT: JAI Press.

Biswas, S., Varma, A., \& Ramaswami, A. (2013). Linking distributive and procedural justice to employee engagement through social exchange: A field study in India. International Journal of Human Resource Management, 24, 1570-1587.

Björkman, I., Ehrnrooth, M., Mäkelä, K., Smale, A., \& Sumelius, J. (2013). Talent or not? Employee reactions to talent identification. Human Resource Management, 52(8), 195-214.

Blau, P. M. (1964). Exchange and power in social life. New York: Wiley.

Buckley, M., Beu, D., Frink, D., Howard, J., Berkson, H., Mobbs, T., et al. (2001). Ethical issues in human resource systems. Human Resource Management Review, 11, 11-29.

Cappelli, P. (2008). Talent management for the 21st century. Harvard Business Review, 86(3), 74-81.

Cohen-Charash, Y., \& Spector, P. E. (2001). The role of justice in organizations: A meta-analysis. Organizational Behavior and Human Decision Processes, 86(2), 278-321.

Collier, J., \& Esteban, R. (2007). Corporate social responsibility and employee commitment. Business Ethics: A European Review, 16(1), 19-33.

Collings, D. G., \& Mellahi, K. (2009). Strategic Talent Management: A review and research agenda. Human Resource Management Review, 19(4), 304-313.

Collings, D. G., Scullion, H., \& Vaiman, V. (2015). Talent management: Progress and prospects. Human Resource Management Review, 25(3), 233-235.

Colquitt, J. A. (2001). On the dimensionality of organizational justice: A construct validation of a measure. Journal of Applied Psychology, 86, 386-400.

Colquitt, J. A., Conlon, D. E., Wesson, M. J., Porter, C. O. L. H., \& Yee Ng, K. (2001). Justice at the millennium: A meta-analytic review of 25 years of organizational justice research. Journal of Applied Psychology, 86(3), 425-445.

Cosier, R. A., \& Dalton, D. R. (1983). Equity theory and time: A reformulation. Academy of Management Review, 8, 311-319.

Cropanzano, R., Bowen, D. E., \& Gilliland, S. W. (2007). The Management of Organizational Justice. Academy of Management Perspectives, 21(4), 34-48.

Cropanzano, R., \& Folger, R. (1991). Procedural justice and worker motivation. In R. M. Steers \& L. W. Porter (Eds.), Motivation and work behavior (5th ed., pp. 131-143). New York: McGrawHill.

Cropanzano, R., \& Mitchell, M. (2005). Social exchange theory: An interdisciplinary review. Journal of Management, 31(6), 874-900.

Downs, Y., \& Swailes, S. (2013). A capability approach to organizational talent management. Human Resource Development International, 16(3), 267-281.

Dries, N. (2013). The psychology of talent management: A review and research agenda. Human Resource Management Review, 23(4), 272-285. 
Emerson, R. M. (1976). Social exchange theory. Annual Review of Sociology, 2, 335-362.

Erdogan, B. (2002). Antecedents and consequences of justice perceptions in performance appraisals. Human Resource Management Review, 12, 555-578.

Festing, M., \& Schäfer, L. (2014). Generational challenges to talent management: A framework for talent retention based on the psychological-contract perspective. Journal of World Business, 49(2), 262-271.

Festing, M., Schäfer, L., \& Scullion, H. (2013). Talent management in medium-sized German companies: An explorative study and agenda for future research. International Journal of Human Resource Management, 24(9), 1872-1893.

Folger, R. (1986). Rethinking equity theory: A referent cognitions model. In H. W. Bierhoff, R. L. Cohen, \& J. Greenberg (Eds.), Justice in social relations. New York: Plenum Press.

Frank, F. D., Finnegan, R. P., \& Taylor, C. R. (2004). The race for talent: Retaining and engaging workers in the 21st century. Human Resource Planning, 27(3), 12-25.

Gallardo-Gallardo, E., Dries, N., \& Gonzalez-Cruz, T. (2013). What is the meaning of 'talent' in the world of work? Human Resource Management Review, 23(4), 290-300.

Garavan, T. N., Carbery, R., \& Rock, A. (2012). Mapping talent development: definition, scope and architecture. European Journal of Training \& Development, 36(1), 5-24.

Gelens, J., Dries, N., Hofmans, J., \& Pepermans, R. (2013). The role of perceived organizational justice in shaping the outcomes of talent management: A research agenda. Human Resource Management Review, 23(4), 341-353.

Gelens, J., Hofmans, J., Dries, N., \& Pepermans, R. (2014). Talent management and organisational justice: employee reactions to high potential identification. Human Resource Management Journal, 4(2), 159-175.

Ghosh, P., Rai, A., \& Sinha, A. (2014). Organizational justice and employee engagement: Exploring the linkage in public sector banks in India. Personnel Review, 43(4), 628-652.

Glass, R. S., \& Wood, W. A. (1996). Situational determinants of software piracy: An equity theory perspective. Journal of Business Ethics, 15(11), 1189-1198.

Godkin, L. (2014). Mid-management, employee engagement, and the generation of reliable sustainable corporate social responsibility. Journal of Business Ethics, 130(1), 15-28.

Gouldner, A. W. (1960). The norm of reciprocity: A preliminary statement. American Sociological Review, 25(2), 161-178.

Greenberg, J. (1990). Organizational justice: Yesterday, today, and tomorrow. Journal of Management, 16(2), 399-432.

Greenberg, J., \& Folger, R. (1983). Procedural justice, participation and the fair process effect in groups and organizations. In P. B. Paulus (Ed.), Basic group processes. New York: SpringerVerlag.

Greenwood, M. R. (2002). Ethics and HRM: A review and conceptual analysis. Journal of Business Ethics, 36(3), 261-278.

Harter, J. K., Schmidt, F. L., \& Hayes, T. L. (2002). Business unit level relationship between employee satisfaction, employee engagement, and business outcomes: A meta-analysis. Journal of Applied Psychology, 87(2), 268-279.

Hayibor, S. (2017). Is fair treatment enough? Augmenting the fairness-based perspective on stakeholder behaviour. Journal of Business Ethics, 140, 43-64

Haynie, J. J., Mossholder, K. W., \& Harris, S. G. (2016). Justice and job engagement: The role of senior management trust. Journal of Organizational Behavior, 37(6), 889-910.

He, H., Zhu, W., \& Zheng, X. (2014). Procedural justice and employee engagement: Roles of organizational identification and moral identity centrality. Journal of Business Ethics, 122(4), 681-695.
Hofmans, J. (2012). Individual differences in equity models. Psycologica, 33, 473-482.

Homans, G. C. (1958). Social behavior as exchange. American Journal of Sociology, 63(6), 597-606.

Homans, G. C. (1961). Social behavior: Its elementary forms. New York: Harcourt, Brace, and World.

Hurrell, S. A. (2016). Rethinking the soft skills deficit blame game: Employers, skills withdrawal and the reporting of soft skills gaps. Human Relations, 69(3), 605-628.

Huselid, M. A., \& Becker, B. E. (2011). Bridging micro \& macro domains: Workforce differentiation and strategic human resource management. Journal of Management, 37, 421-428.

Iles, P., Preece, D., \& Chuai, X. (2010). Talent management as a management fashion in HRD: Towards a research agenda. Human Resource Development International, 13(2), 125-145.

Jepsen, D. M., \& Rodwell, J. (2012). Female perceptions of organizational justice. Gender, Work and Organization, 19(6), 723-740.

Kahn, W. A. (1990). Psychological conditions of personal engagement and disengagement at work. The Academy of Management Journal, 33(4), 692-724.

Katou, A. A. (2013). Justice, trust and employee reactions: An empirical examination of the HRM system. Management Research Review, 36(7), 674-699.

Khoreva, V., Vaiman, V., \& Van Zalk, M. (2017). Talent management practice effectiveness: investigating employee perspective. Employee Relations, 39, 19-33.

Kinnie, N., Hutchinson, S., Purcell, J., Rayton, B., \& Swart, J. (2005). Satisfaction with HR practices and commitment to the organization: why one size does not fit all. Human Resource Management Journal, 15(4), 9-29.

Lacey, M. Y., \& Groves, K. (2014). Talent management collides with corporate social responsibility: Creation of inadvertent hypocrisy. Journal of Management Development, 33(4), 399-409.

Lepak, D. P., \& Snell, S. A. (1999). The human resource architecture: Toward a theory of human capital allocation and development. The Academy of Management Review, 24(1), 31-48.

Leventhal, G. S. (1976). Fairness in Social Relationships. In J. W. Thibaut, J. T. Spence, \& R. C. Carson (Eds.), Contemporary Topics in Social Psychology. Morristown, NJ: General Learning Press.

Leventhal, G. S. (1980). What should be done with equity theory? New approaches to the study of fairness in social relationships. New York: Plenum.

Lewis, R. E., \& Heckman, R. J. (2006). Talent management: A critical review. Human Resource Management Review, 16, 139-154.

$\mathrm{Li}, \mathrm{H}$. (2012) A study on the relationships among organizational justice, organizational identification, and work engagement: The evidence from the hi-tech service industries. In 2012 International Joint Conference on Service Sciences, Service Innovation in Emerging Economy: Cross-Disciplinary and Cross-Cultural Perspective, IJCSS 2012, 2012. 72-77.

Macey, W. H., \& Schneider, B. (2008). The Meaning of Employee Engagement. Industrial and Organizational Psychology, 1(1), 3-30.

Mahajan, A., \& Benson, P. (2013). Organisational justice climate, social capital and firm performance. Journal of Management Development, 32(7), 721-736.

Malik, A. R., \& Singh, P. (2014). 'High potential' programs: Let's hear it for ' $B$ ' players. Human Resource Management Review, 24(4), 330-346.

Marescaux, E., De Winne, S., \& Sels, L. (2013). HR practices and affective organisational commitment: (When) does HR differentiation pay off? Human Resource Management Journal, 23(4), 329-345. 
Maslach, C., Schaufelli, W. B., \& Leiter, M. P. (2001). Job burnout. Annual Review of Psychology, 52, 397-422.

Masterson, S. S., Lewis, K., Goldman, B. M., \& Taylor, M. S. (2000). Integrating justice and social exchange: the differing effects of fair procedures and treatment on work relationships. The Academy of Management Journal, 43(4), 738-748.

May, D. R., Gilson, R. L., \& Harter, L. M. (2004). The psychological conditions of meaningfulness, safety and availability and the engagement of the human spirit at work. Journal of Occupational \& Organizational Psychology, 77, 11-37.

McFarlin, D. B., \& Sweeney, P. D. (1992). Distributive and procedural justice as predictors of satisfaction with personal and organizational outcomes. Academy of Management Journal, 35(3), 626-637.

Meyers, M. C., Collings, D. G. \& Paauwe, J. (2015). Talent Management: Towards Balance in Theory and Research. In: Academy of Management Annual Meeting Proceedings, 1-1.

Meyers, M. C., Van Woerkom, M., \& Dries, N. (2013). TalentInnate or acquired? Theoretical considerations and their implications for talent management. Human Resource Management Review, 23(4), 305-321.

Minbaeva, D., \& Collings, D. G. (2013). Seven myths of global talent management. The International Journal of Human Resource Management, 24, 1762-1776.

Mintzberg, H. (1978). Patterns in Strategy Formation. Management Science, 24(9), 934-948.

O’Connor, E. \& Crowley-Henry, M. (2015). Exclusive talent management, perceived organizational justice \& employee engagement: Bridging the literature. In University Forum for Human Resource Development Conference University College Cork, Ireland.

Pfeffer, J. (2001). Fighting the war for talent is hazardous to your organization's health. Organizational Dynamics, 29(4), 248-259.

Pritchard, R. D. (1968). Equity theory. A review and critique. Organizationial Behavior and Human Performance, 4(2), 176-211.

Purang, P. (2011). Organisational justice and affective commitment: The mediating role of perceived organisational justice. Asian Academy of Management Journal, 16(1), 141-156.

Rich, B. L., Lepine, J. A., \& Crawford, E. R. (2010). Job engagement: Antecedents and effects on job performance. Academy of Management Journal, 53(3), 617-635.

Roof, R. A. (2015). The association of individual spirituality on employee engagement: The spirit at work. Journal of Business Ethics, 130(3), 585-599.

Saks, A. M. (2006). Antecedents and consequences of employee engagement. Journal of Managerial Psychology, 21(7), 600-619.

Saks, A. M., \& Gruman, J. A. (2014). What do we really know about employee engagement? Human Resource Development Quarterly, 25(2), 155-182.

Schaufeli, W., Salanova, M., González-Roma, V., \& Bakker, A. (2002). The measurement of engagement and burnout: A two sample confirmatory factor analytic approach. Journal of Happiness Studies, 3, 71-92.

Schminke, M., Arnaud, A., \& Taylor, R. (2014). Ethics, values, and organizational justice: Individuals, organizations, and beyond. Journal of Business Ethics, 130(3), 727-736.

Sheehan, M., \& Anderson, V. (2015). Talent management and organizational diversity: A call for research. Human Resource Development Quarterly, 26(4), 349-358.

Shuck, B. (2011). Four emerging perspectives of employee engagement: An integrative literature review. Human Resource Development Review, 10, 304-328.

Shuck, B., \& Reio, T. G., Jr. (2014). Employee engagement and wellbeing: A moderation model and implications for practice. Journal of Leadership \& Organizational Studies, 21(1), 43-58.
Skarlicki, D. P., \& Folger, R. (1997). Retaliation in the workplace: The roles of distributive, procedural, and interactional justice. Journal of Applied Psychology, 82(3), 434-443.

Slack, R. E., Corlett, S., \& Morris, R. (2015). Exploring employee engagement with (corporate) social responsibility: A social exchange perspective on organisational participation. Journal of Business Ethics, 127(3), 537-548.

Snell, A. (2009). Tackling the challenges of employee engagement. Strategic HR Review, 8(2), 37-38.

Soni, H. (2014). Ethical talent management: The hall mark of contemporary HRM. International Journal of Research in Management \& Technology, 4(2), 122-130.

Swailes, S. (2013a). The ethics of talent management. Business Ethics: A European Review, 22(1), 32-46.

Swailes, S. (2013b). Troubling some assumptions: A response to "The role of perceived organizational justice in shaping the outcomes of talent management: A research agenda”. Human Resource Management Review, 23(4), 354-356.

Swailes, S., \& Blackburn, M. (2016). Employee reactions to talent pool membership. Employee Relations, 38(1), 112-128.

Swailes, S., Downs, Y., \& Orr, K. (2014). Conceptualising inclusive talent management: Potential, possibilities and practicalities. Human Resource Development International, 17(5), 529-544.

Tansley, C., Kirk, S., \& Tietze, S. (2013). The currency of talent management-A reply to "talent management and the relevance of context: Towards a pluralistic approach”. Human Resource Management Review, 23, 337-340.

Tatli, A., Vassilopoulou, J., \& Ozbilgin, M. F. (2013). An unrequited affinity between talent shortages and untapped female potential: The relevance of gender quotas for talent management in high growth potential economies of the Asia Pacific region. International Business Review, 22(3), 539-553.

Thomas, M., \& Rowland, C. (2014). Leadership, Pragmatism and Grace: A Review. Journal of Business Ethics, 123(1), 99-111.

Thornton, M. A., \& Rupp, D. E. (2016). The joint effects of justice climate, group moral identity, and corporate social responsibility on the prosocial and deviant behaviors of groups. Journal of Business Ethics, 137, 677-697.

Thunnissen, M., Boselie, P., \& Fruytier, B. (2013). A review of talent management: 'infancy or adolescence?'. The International Journal of Human Resource Management, 24(9), 1744-1761.

Van Buren, H. J., III. (2008). Fairness and the main management theories of the Twentieth Century: A historical review, 1900-1965. Journal of Business Ethics, 82, 633-644.

Vosloban, R. I. (2013). Employee engagement concept-A theoretical and practical approach. Contemporary Readings in Law and Social Justice, 5(2), 759-765.

Wan, H. L., Sulaiman, M., \& Omarb, A. (2012). Procedural justice in promotional decisions. Asia Pacific Business Review, 18(1), 99-121.

Wooten, K. C., \& Cobb, A. T. (1999). Career development and organizational justice: Practice and research implications. Human Resource Development Quarterly, 10(2), 173-178.

Wright, P. M. \& Nishii, L. H. (2006). Strategic HRM and Organizational Behavior: Integrating Multiple Levels of Analysis. In CAHRS Working Paper (\#07-03). Cornell University, School of Industrial and Labor Relations, Center for Advanced Human Resource Studies Center for Advanced Human Resource Studies Working Papers Series. Ithica: NY.

Wright, P. M., \& Snell, S. A. (1998). Toward a unifying framework for exploring fit and flexibility in strategic human resource management. The Academy of Management Review, 24(1), 31-48. 